\title{
Pharmacokinetics and first-pass metabolism of astaxanthin in rats
}

\author{
Hye Duck Choi, Hee Eun Kang, Si Hyung Yang, Myung Gull Lee and Wan Gyoon Shin* \\ College of Pharmacy and Research Institute of Pharmaceutical Sciences, Seoul National University, San 56-1, Sillim-Dong, \\ Gwanak-Gu, Seoul 151-742, South Korea
}

(Received 2 June 2010 - Revised 4 August 2010 - Accepted 6 August 2010 - First published online 7 September 2010)

\begin{abstract}
Astaxanthin is a carotenoid with antioxidant, anti-cancer and anti-inflammatory properties. The pharmacokinetics of astaxanthin after its intravenous $(5,10$, and $20 \mathrm{mg} / \mathrm{kg}$ ) and oral $(100$ and $200 \mathrm{mg} / \mathrm{kg})$ administration and its first-pass extraction ratios after its intravenous, intraportal or intragastric $(20 \mathrm{mg} / \mathrm{kg})$ administration were evaluated in rats. The pharmacokinetic parameters of astaxanthin were dose dependent after its intravenous administration, due to the saturable hepatic metabolism of astaxanthin, but dose independent after oral administration. The gastrointestinal absorption of astaxanthin followed the flip-flop model. The hepatic and gastrointestinal first-pass extraction ratios of astaxanthin were approximately 0.490 and 0.901 , respectively. Astaxanthin was metabolised primarily by hepatic cytochrome $P-4501 \mathrm{~A} 1 / 2$ in rats. Astaxanthin was unstable up to $4 \mathrm{~h}$ incubation in four rat gastric juices and up to $24 \mathrm{~h}$ incubation in various buffer solutions having a $\mathrm{pH}$ of $1-13$. The tissue/plasma ratios of astaxanthin at 8 and $24 \mathrm{~h}$ after its oral administration $(100 \mathrm{mg} / \mathrm{kg})$ were greater than unity for all tissues studied, except in the heart, at $8 \mathrm{~h}$, indicating that the rat tissues studied had high affinity for astaxanthin.
\end{abstract}

Key words: Astaxanthin: Carotenoids: Pharmacokinetics: Rats

Astaxanthin $\left(3,3^{\prime}\right.$-dihydroxy- $\beta, \beta^{\prime}$-carotene- $4,4^{\prime}$-dione) is a lipophilic pigment with a reddish colour, which is naturally synthesised by algae or plants, and is primarily distributed in marine organisms. For example, salmon, shrimp, and crab are representative astaxanthin-containing seafood and their red colour is related to astaxanthin. Also, astaxanthin is commercially available as a nutritional supplement in many countries including the USA, Sweden, Japan and South Korea. Astaxanthin belongs to the xanthophyll group, which are oxygenated derivatives of carotenes. The xanthophylls and carotenes are two major groups of carotenoids that possess a number of health benefits. Like other carotenoids, astaxanthin has antioxidant, anticancer and anti-inflammatory activities ${ }^{(1)}$. However, astaxanthin's most beneficial property is its activity as a potent antioxidant. Miki $^{(2)}$ reported that the antioxidant activity of astaxanthin was more powerful than that of $\beta$-carotene or $\alpha$-tocopherol, well-known antioxidants. Moreover, the biological activities of astaxanthin have been examined in clinical studies regarding CVD, male infertility, functional dyspepsia and age-related maculopathy ${ }^{(3-6)}$.

In humans, the bioavailability of carotenoids is low and variable. It ranges from 10 to $50 \%$ of a given dose, due to low solubility in gastrointestinal tract juices, leading to poor absorption by the epithelial cells of the small intestine $^{(7)}$. It has been reported that the low bioavailability of astaxanthin is improved by lipid-based formulations in human subjects ${ }^{(8)}$. Also, the oral bioavailability of astaxanthin could be improved by timing the dose to be taken either before or after a meal ${ }^{(9)}$. Showalter et al. ${ }^{(10)}$ found in mice that after both single and multiple oral administrations, the total area under the concentration-time curve (AUC) of astaxanthin in the liver was greater than that in the plasma, suggesting considerable uptake by the liver. Petri \& Lundebye ${ }^{(11)}$ evaluated the tissue distribution of astaxanthin after oral administration for 2 weeks in rats and found that astaxanthin accumulated primarily in the spleen, kidneys, adrenals, liver, skin and eyes. Recently, several studies reported the metabolism of astaxanthin in animals and human subjects. On the basis of in vivo human (per oral administration) and in vitro human hepatocyte studies, astaxanthin is metabolised into 3-hydroxy-4oxo- $\beta$-ionol and 3 -hydroxy- $4-\beta$-ionone ${ }^{(12)}$. On the basis of in vitro primary cultures of rat hepatocytes, astaxanthin is metabolised to 3 -hydroxy-4-oxo- $\beta$-ionone and its reduced form, 3-hydroxy-4-oxo-7,8-dihydro- $\beta$-ionone, and their

Abbreviations: AUC, the total area under the concentration-time curve; $\mathrm{CL}$, time-averaged total body clearance; $\mathrm{CL}_{\mathrm{R}}$, renal clearance; $\mathrm{CL}_{\mathrm{NR}}$, non-renal clearance; $C_{\max }$, peak plasma concentration.

*Corresponding author: Professor W. G. Shin, fax +82 2766 8556, email wgshin@snu.ac.kr 
glucuronide conjugates ${ }^{(13)}$. However, the biological effects of the metabolites of astaxanthin have not been thoroughly studied. Also, the pharmacokinetics and first-pass extraction of astaxanthin were not reported.

The objective of the present study was to determine the pharmacokinetics of astaxanthin after its intravenous (at doses of 5, 10 and $20 \mathrm{mg} / \mathrm{kg}$ ) and oral (at doses of 100 and $200 \mathrm{mg} / \mathrm{kg}$ ) administration, and its gastrointestinal and hepatic first-pass extraction ratios, following intravenous, intragastric or intraportal administration at a dose of $20 \mathrm{mg} / \mathrm{kg}$ in rats. Hepatic cytochrome $P-4501 \mathrm{~A} 1 / 2$, an enzyme responsible for the metabolism of astaxanthin, and its tissue distribution in rats were also examined.

\section{Materials and methods}

\section{Chemicals}

Astaxanthin, $\beta$-apo-8-carotenal (internal standard for the analysis of astaxanthin by HPLC), 3-methylcholanthrene (inducer of cytochrome $P-4501 \mathrm{~A} 1 / 2$ in rats ${ }^{(14)}$ ), maize oil and $N, N$-dimethylacetamide were purchased from SigmaAldrich Corporation (St Louis, MO, USA). Polyethylene glycol 400 was from Showa Chemical Company (Tokyo, Japan). Other chemicals were of reagent or HPLC grade (Mallinckrodt Baker, Inc., Phillipsburg, NJ, USA).

\section{Animals}

The protocol for the present animal study was approved by the Institute of Laboratory Animal Resources of Seoul National University, Seoul, South Korea.

Male Sprague-Dawley rats (7-8 weeks old, weighing 240-330 g) were purchased from Charles River Company Korea (Orient, Seoul, South Korea). Rats were maintained in a light-controlled room (light: 7.00-19.00 hours, dark: 19.00-7.00 hours), kept at a temperature of $22 \pm 2^{\circ} \mathrm{C}$ and a relative humidity of $55 \pm 5 \%$ (Animal Center for Pharmaceutical Research, College of Pharmacy, Seoul National University). Rats were housed in metabolism cages (Tecniplast, Varese, Italy) maintained with a ad libitum supply of filtered pathogen-free air, food (Agribrands Purina Korea, Pyeongtaek, South Korea) and water.

\section{Intravenous and oral studies}

The procedures used for the pretreatment of rats including the cannulation of the carotid artery and the jugular vein were similar to a previously reported method ${ }^{(15)}$. Cannulation of the carotid artery for blood sampling was done early in the morning and all intravenous drugs were delivered through the access in the jugular vein. Astaxanthin (dissolved in polyethylene glycol $400-N, N$-dimethylacetamide $(50: 50, \mathrm{v} / \mathrm{v})$ at doses of $5(n 8), 10(n 8)$ and 20 ( $n$ 6) $\mathrm{mg}(2 \mathrm{ml}) / \mathrm{kg}$ was manually infused for $1 \mathrm{~min}$ via the jugular vein. Blood samples, approximately $0.22 \mathrm{ml}$ each, were collected via the carotid artery at 0 (control), 1 (end of the infusion), 5, 15, 30, 60, 90, 120, 240, 360, $480,720,1200(5 \mathrm{mg} / \mathrm{kg})$ and $1440 \mathrm{~min}(10$ and $20 \mathrm{mg} / \mathrm{kg})$ after the start of the intravenous infusion of astaxanthin. Heparinised $0.9 \%$ NaCl-injectable solution (20 units $/ \mathrm{ml}$; $0.3 \mathrm{ml}$ ) was used to flush the cannula after each blood sampling to prevent blood clotting. Each blood sample was immediately centrifuged and $100 \mu \mathrm{l}$ of each plasma sample was stored at $-70^{\circ} \mathrm{C}$ until its use in the HPLC analysis of astaxanthin. The procedures used for the preparation and handling of the $24 \mathrm{~h}$ urine sample were similar to a previously reported method ${ }^{(15)}$. Astaxanthin, using the same solution as used in the intravenous study, at doses of $100(n$ 8) and $200(n$ 9) $\mathrm{mg}(5 \mathrm{ml}) / \mathrm{kg}$ was administered orally using a gastric gavage to rats. Blood sampling time schedules were $0,2,4,6,7,8,12,24,30,36(100 \mathrm{mg} / \mathrm{kg})$ and $48 \mathrm{~h}(200 \mathrm{mg} / \mathrm{kg})$ after the oral administration of astaxanthin. Other procedures for the oral study were similar to those of the intravenous study. In the present oral studies, higher oral doses than in human subjects ( $40 \mathrm{mg}$ ) were used to obtain a complete and more reliable pharmacokinetic parameters because the gastrointestinal absorption of astaxanthin is low.

\section{Measurement of first-pass extraction ratio of astaxanthin} in rats

The procedures used were similar to the previously reported methods ${ }^{(16,17)}$. The vein from the caecum was cannulated and the cannula was pushed forward about $4.0 \mathrm{~cm}$ toward the liver through the portal vein to minimise impaired blood flow into the portal vein ${ }^{(16)}$. For the intravenous administration ( $n$ 4), astaxanthin, using the same solution as used in the intravenous study, at a dose of $20 \mathrm{mg}(2 \mathrm{ml}) / \mathrm{kg}$ was infused for $30 \mathrm{~min}$ via the jugular vein. The same volume of the vehicle (polyethylene glycol 400-N,N-dimethylacetamide (50:50, v/v)) was infused for $30 \mathrm{~min}$ into the portal vein and instilled into the stomach using a syringe after $4-5 \mathrm{~h}$ recovery from the light diethyl ether anaesthesia. All intravenous administration was applied with the assistance of an infusion pump (Model 2400-006; Harvard Instrument, South Natick, MA, USA). For intraportal administration ( $n$ 3), the same dose of astaxanthin was infused for $30 \mathrm{~min}$ via the portal vein and the same volume of the vehicle was infused for $30 \mathrm{~min}$ into the jugular vein and instilled into the stomach. For the intragastric administration ( $n$ 4), the same dose of astaxanthin was instilled into the stomach and the same volume of the vehicle was infused for $30 \mathrm{~min}$ via the jugular and portal veins. Blood samples (approximately $0.22 \mathrm{ml}$ each) were collected via the carotid artery at $0,15,30$ (end of the infusion), 35, 45, 60, 90, 150, 270 and $510 \mathrm{~min}$ for the infusion study, and at 0, 60, 120, 180, 240, 360 and $480 \mathrm{~min}$ for the instillation study. 
Administration of 3-methylcholanthrene, a cytochrome $\mathrm{P}-4501 \mathrm{~A} 1 / 2$ inducer, in rats

Rats received four daily intraperitoneal injections of $20 \mathrm{mg}$ $(3.3 \mathrm{ml}) / \mathrm{kg}$ of 3 -methylcholanthrene group $)^{(18,19)}$ or $3.3 \mathrm{ml} / \mathrm{kg}$ of maize oil (3-methylcholanthrene control rats group). During the pretreatment, rats had free access to food and water. The experiment was performed on day 5 after the start of the pretreatment. Other procedures were similar to those in the previously described intravenous study. $\mathrm{T}$ and $\mathrm{C}$ refer to the treated and control, respectively.

\section{Tissue distribution of astaxanthin after its oral administration in rats}

The procedures used were similar to a previously reported method $^{(20)}$. Astaxanthin, the same solution as used in the oral study, at a dose of $100 \mathrm{mg}(5 \mathrm{ml}) / \mathrm{kg}$ was administered orally using a gastric gavage tube in rats. Approximately, $1 \mathrm{~g}$ of each liver, kidney, heart, stomach, lung, small intestine, large intestine, spleen, fat, muscle and brain was quickly excised after 8 and $24 \mathrm{~h}$, respectively ( $n 3$, each) after cervical dislocation. Each tissue sample was rinsed with cold $0.9 \% \mathrm{NaCl}$-injectable solution, blotted dry with tissue paper and weighed. Then, each tissue was homogenised with four volumes of $0.9 \% \mathrm{NaCl}$-injectable solution in a tissue homogeniser (Ultra-Turrax T25; Janke \& Kunkel, IKA-Labortechnik, Staufeni, Germany) and centrifuged. Two $50 \mu \mathrm{l}$ aliquots of plasma samples or the supernatant of each tissue homogenate were stored at $-70^{\circ} \mathrm{C}$ until use for the HPLC analysis of astaxanthin.

\section{Stability of astaxanthin}

The procedures used were similar to a previously reported method $^{(21)}$. An astaxanthin stock solution (dissolved in chloroform-hexane $(30: 70, \mathrm{v} / \mathrm{v}))$ was spiked $(10 \mu \mathrm{l} / \mathrm{ml})$ in each test-tube that contained four rat gastric juices and various buffer solutions with $\mathrm{pH}$ ranging from 1 to 13 to produce an astaxanthin concentration of $2 \mu \mathrm{g} / \mathrm{ml}$. After vortex-mixing, each sample was incubated in a waterbath shaker kept at a temperature of $37.8^{\circ} \mathrm{C}$ and at a rate of 50 oscillations/min at 0, 15, 30, 60, 120 and $240 \mathrm{~min}$ for rat gastric juices and at 2, 4, 6, 8, 12 and $24 \mathrm{~h}$ for various buffer solutions. Then, $100 \mu$ l were sampled from each test-tube. The concentrations of astaxanthin in the previously mentioned samples were analysed as soon as the sample was collected.

\section{HPLC analysis of astaxanthin}

Concentrations of astaxanthin were analysed by a slight modification of the reported HPLC method ${ }^{(9)}$. Briefly, $600 \mu \mathrm{l}$ of acetone containing $2 \mu \mathrm{g} / \mathrm{ml}$ of $\beta$-apo- 8 -carotenal, as an internal standard, was added to $100 \mu$ l of a sample. After vortex-mixing for $1 \mathrm{~min}$, the mixture was extracted with $600 \mu$ l of hexane. The organic layer was collected and dried (Dry thermobath, Eyela, Tokyo, Japan) under a gentle stream of $\mathrm{N}_{2}$ gas at $25^{\circ} \mathrm{C}$. A $100 \mu \mathrm{l}$ aliquot of the mobile phase was added to reconstitute the residue and $30 \mu \mathrm{l}$ was directly injected onto a normal-phase HPLC column. The mobile phase, hexane-acetone (75:25, v/v), was run at a flow-rate of $1.0 \mathrm{ml} / \mathrm{min}$, and the column eluent was monitored using a UV detector at $470 \mathrm{~nm}$, at room temperature. The retention times of the internal standard and astaxanthin were approximately 2.3 and $4.8 \mathrm{~min}$, respectively. The detection limits of astaxanthin in rat plasma and urine samples were 0.01 and $0.05 \mu \mathrm{g} / \mathrm{ml}$, respectively. The $\mathrm{CV}$ of astaxanthin in plasma and urine samples were $<9.6$ and $7.8 \%$, respectively.

\section{Pharmacokinetic analysis}

Standard methods ${ }^{(22)}$ were used to calculate the following pharmacokinetic parameters using a non-compartmental analysis (WinNonlin ${ }^{\circledR}$; professional edition version 2.1; Pharsight, Mountain View, CA, USA): the AUC ${ }^{(23)}$, terminal half-life, time-averaged total body, renal and non-renal clearances $\left(\mathrm{CL}, \mathrm{CL}_{\mathrm{R}}\right.$ and $\mathrm{CL}_{\mathrm{NR}}$, respectively), mean residence time and apparent volume of distribution at steady state. The peak plasma concentration $\left(C_{\max }\right)$ and time to reach $C_{\max }$ were directly read from the experimental data. Doses were normalised based on $1 \mathrm{mg} / \mathrm{kg}$ of astaxanthin for AUC and $C_{\max }$ for statistical analysis.

\section{Statistical analysis}

Data were analysed individually and a value of $P<0.05$ was deemed to indicate statistical significance. Statistical evaluations were performed using Student's $t$ test between the two means for the unpaired data or Duncan's multiple range test of SPSS (Chicago, IL, USA) a posteriori ANOVA among the three means for the unpaired data. All the data are expressed as mean and standard deviation, except median (range) for time to reach the $C_{\max }$.

\section{Results}

Pharmacokinetics of astaxanthin after its intravenous and oral administration in rats

The mean arterial plasma concentration-time profiles for the intravenous administration of astaxanthin at doses of 5,10 and $20 \mathrm{mg} / \mathrm{kg}$ are shown in Fig. 1(a). The relevant pharmacokinetic parameters are listed in Table 1 . The dose-normalised AUC of astaxanthin at a dose of $20 \mathrm{mg} /$ $\mathrm{kg}(61.0$ (SD 15.7) $\mu \mathrm{g} \mathrm{min} / \mathrm{ml}$ ) was significantly greater by $54.8 \%$ than that at $5 \mathrm{mg} / \mathrm{kg}(39.4$ (SD 9.90) $\mu \mathrm{g} \mathrm{min} / \mathrm{ml}$ ). Similar results were obtained from $\mathrm{CL}$ and $\mathrm{CL}_{\mathrm{NR}}$. The $\mathrm{CL}_{\mathrm{R}}$ at 10 and $20 \mathrm{mg} / \mathrm{kg}$ were significantly slower (66.4 and $86.0 \%$, respectively) than that at $5 \mathrm{mg} / \mathrm{kg}$. These data suggest that astaxanthin exhibits dose-dependent 

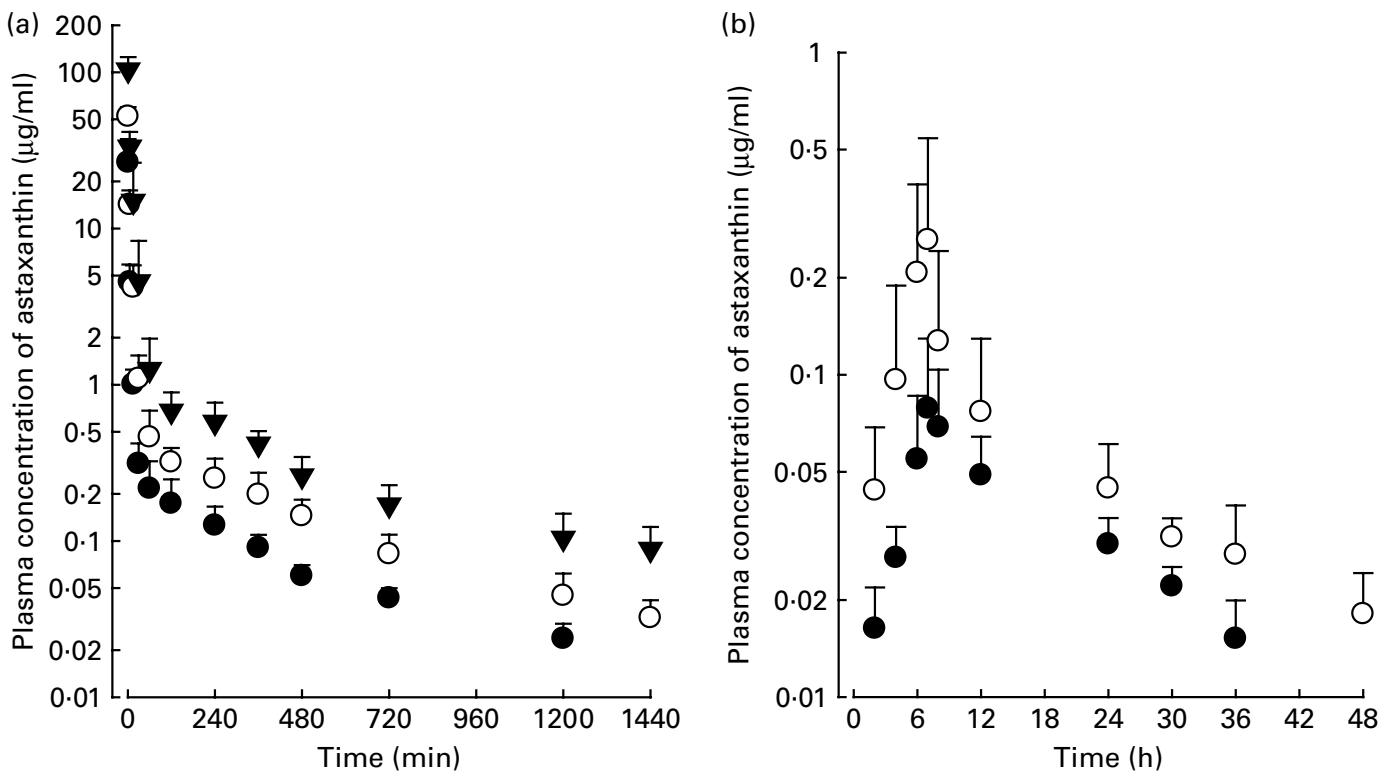

Fig. 1. Mean arterial plasma concentration-time profiles of astaxanthin after its intravenous administration (a) at doses of 5 (๑; $n$ 8), 10 ( 0 ; $n$ 8), and $20(\mathbf{\nabla} ; n 6) \mathrm{mg} / \mathrm{kg}$ and oral administration (b) at doses of $100(\bullet ; n 8)$ and $200(\bigcirc ; n 9) \mathrm{mg} / \mathrm{kg}$ in rats. Bars indicate standard deviations.

pharmacokinetics after three intravenous doses, as studied in rats. The CL and total amount excreted in $24 \mathrm{~h}$ urine were almost negligible.

The mean arterial plasma concentration-time profiles for the oral administration of astaxanthin at doses of 100 and $200 \mathrm{mg} / \mathrm{kg}$ are shown in Fig. 1(b). The relevant pharmacokinetic parameters are also listed in Table 1. The dose-normalised AUC of astaxanthin at a dose of $100 \mathrm{mg} / \mathrm{kg}(0.773(\mathrm{sD} 0 \cdot 162) \mu \mathrm{g} \mathrm{min} / \mathrm{ml})$ was comparable to that at a dose of $200 \mathrm{mg} / \mathrm{kg}(0.750(\mathrm{SD} 0.385) \mu \mathrm{g} \mathrm{min} / \mathrm{ml})$. The dose-normalised $C_{\max }$ of astaxanthin at a dose of $200 \mathrm{mg} / \mathrm{kg}(1.69(\mathrm{SD} 1.34) \mathrm{ng} / \mathrm{ml})$ was higher than the $C_{\max }$ at a dose of $100 \mathrm{mg} / \mathrm{kg}(0.956(\mathrm{sD} 0.456) \mathrm{ng} / \mathrm{ml})$, but not statistically significant. Similar results were also obtained for other pharmacokinetic parameters. The previously mentioned data suggest that astaxanthin exhibits dose-independent pharmacokinetics after two oral doses of astaxanthin in rats.

\section{Hepatic and gastric first-pass extraction ratios of} astaxanthin in rats

Following the intravenous, intraportal or intragastric administration of astaxanthin at a dose of $20 \mathrm{mg} / \mathrm{kg}$, its mean arterial plasma concentration-time profiles of astaxanthin were determined, as shown in Fig. 2. The AUC of astaxanthin after its intraportal administration (307 (SD 14.8) $\mu \mathrm{gmin} / \mathrm{ml}$ ) was significantly smaller (by $49 \cdot 0 \%$ ) than after its intravenous administration (602 (sD 69.3 ) $\mu \mathrm{g} \mathrm{min} / \mathrm{ml}$ ), suggesting that the hepatic first-pass extraction ratio of astaxanthin after absorption into the portal vein was approximately 0.49 in rats.

The AUC of astaxanthin after its intragastric administration $(30.5$ (SD 4.41$) \mu \mathrm{g} \mathrm{min} / \mathrm{ml}$ ) was significantly smaller, by $90 \cdot 1 \%$, than after intraportal administration. The previously mentioned data suggest that the gastrointestinal first-pass extraction ratio of astaxanthin was approximately 0.901 of the dose in rats.

\section{Pharmacokinetics of astaxanthin in rats pretreated with 3-methylcholanthrene}

The mean arterial plasma concentration-time profiles of astaxanthin after its intravenous administration in rats pretreated with 3-methylcholanthrene and control rats are shown in Fig. 3. Relevant pharmacokinetic parameters are listed in Table 2. Compared with 3-methylcholanthrene control rats rats, the AUC was significantly smaller, by $26.6 \%$, mean residence time was significantly shorter, by $16 \cdot 2 \%$, and $\mathrm{CL}$ and $\mathrm{CL}_{\mathrm{NR}}$ were significantly faster, both by $30 \cdot 1 \%$, in pretreated with 3-methylcholanthrene rats. The previously mentioned data suggest that astaxanthin is metabolised primarily by cytochrome $P-450$ $1 \mathrm{~A} 1 / 2$ in rats.

\section{Tissue distribution of astaxanthin after its oral administration in rats}

The amounts of astaxanthin recovered from each tissue at 8 - and $24 \mathrm{~h}$ after its oral administration at a dose of $100 \mathrm{mg} / \mathrm{kg}$ are listed in Table 3. Tissue:plasma ratios of astaxanthin at 8 and $24 \mathrm{~h}$ were greater than unity for all tissues studied, except for the heart at $8 \mathrm{~h}$. This suggests that rat tissues and organs had a high affinity for astaxanthin and this was supported by the large values of volume of distribution at steady state, $4860-5770 \mathrm{ml} / \mathrm{kg}$ (Table 1 ). 
Fig. 2. Mean arterial plasma concentration-time profiles of astaxanthin after its intravenous $(\bullet ; n)$, intraportal $(O ; n 3)$ and intragastric $(\boldsymbol{\Lambda} ; n 4)$ administration at a dose of $20 \mathrm{mg} / \mathrm{kg}$ in rats. Bars indicate standard deviations.

\section{Stability of astaxanthin}

Astaxanthin was unstable in rat gastric juices: 45.8, 23.1, 49.2 and $56 \cdot 8 \%$ of the spiked amounts of astaxanthin were recovered after $4 \mathrm{~h}$ incubation in four rat gastric juices having $\mathrm{pH}$ of $3 \cdot 0,3 \cdot 5,4.0$ and 4.0 , respectively. Astaxanthin was also unstable up to $24 \mathrm{~h}$ incubation in various buffer solutions: $7 \cdot 1,4 \cdot 8,22 \cdot 8,12 \cdot 6,11 \cdot 0,12 \cdot 6$, $4 \cdot 5,6 \cdot 7,5 \cdot 1,4 \cdot 8,6 \cdot 0,11 \cdot 8$ and $9 \cdot 3 \%$ of the spiked amounts of astaxanthin were recovered in buffer solutions with $\mathrm{pH} 1-13$, respectively. These data suggest that astaxanthin is unstable with regard to chemical and enzymatic degradation.

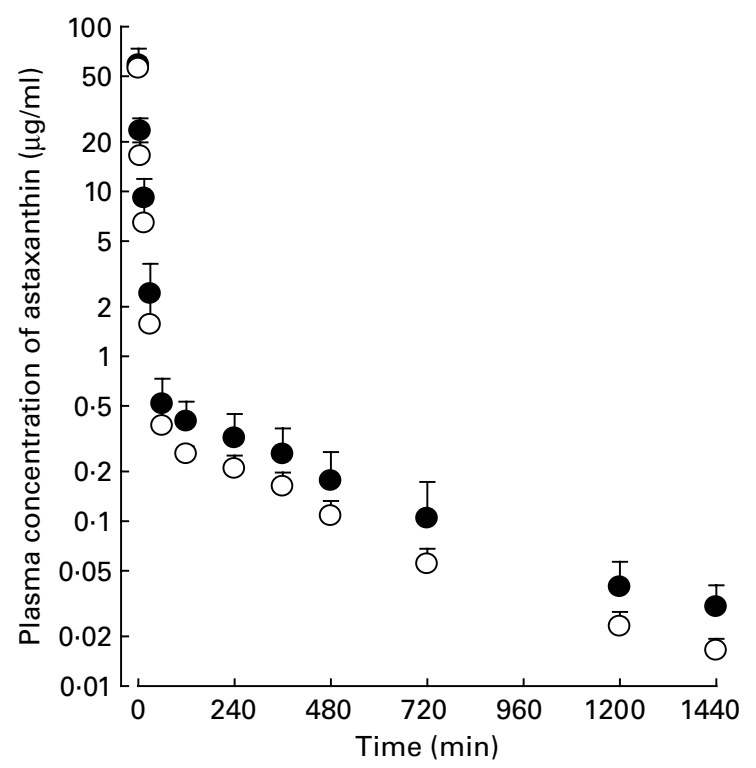

Fig. 3. Mean arterial plasma concentration-time profiles of astaxanthin after its intravenous administration at a dose of $20 \mathrm{mg} / \mathrm{kg}$ in rats pretreated with 3-methylcholanthrene $(0 ; n$ 8) and without 3-methylcholanthrene $(\bullet ; n 8)$. Bars indicate standard deviations. 
Table 2. Pharmacokinetic parameters of astaxanthin after its intravenous administration at a dose of $10 \mathrm{mg} / \mathrm{kg}$ in rats pretreated with 3-methylcholanthrene (MC-T) and without 3-methylcholanthrene (MC-C)

(Mean values and standard deviations)

\begin{tabular}{|c|c|c|c|c|}
\hline \multirow[b]{2}{*}{ Parameters } & \multicolumn{2}{|c|}{ MC-C $(n 8)$} & \multicolumn{2}{|c|}{ MC-T $(n 8)$} \\
\hline & Mean & SD & Mean & SD \\
\hline AUC $(\mu \mathrm{g} \times \min / \mathrm{ml})$ & 680 & 168 & $499^{*}$ & 53.2 \\
\hline Terminal half-life ( $\mathrm{min})$ & 393 & $47 \cdot 1$ & 367 & $75 \cdot 1$ \\
\hline MRT (min) & 173 & $32 \cdot 5$ & 145 & $19 \cdot 7$ \\
\hline $\mathrm{CL}(\mathrm{ml} / \mathrm{min}$ per $\mathrm{kg})$ & $15 \cdot 3$ & 3.84 & $19 \cdot 9^{*}$ & 1.98 \\
\hline $\mathrm{CL}_{\mathrm{R}}(\mathrm{ml} / \mathrm{min}$ per $\mathrm{kg})$ & 0.00677 & 0.00551 & 0.0144 & 0.0209 \\
\hline $\mathrm{CL}_{\mathrm{NR}}(\mathrm{ml} / \mathrm{min}$ per $\mathrm{kg})$ & $15 \cdot 3$ & 3.84 & $19 \cdot 9^{*}$ & 1.98 \\
\hline$V_{\mathrm{ss}}(\mathrm{ml} / \mathrm{kg})$ & 2560 & 541 & 2910 & 516 \\
\hline$A e_{0-24 \mathrm{~h}}(\%$ of dose $)$ & 0.0482 & 0.0507 & 0.0724 & 0.103 \\
\hline
\end{tabular}

AUC, total area under the plasma concentration-time curve from time zero to infinity; MRT, mean residence time; CL, time-averaged total body clearance; $\mathrm{CL}_{\mathrm{R}}$, time-averaged renal clearance; $\mathrm{CL}_{\mathrm{NR}}$, time-averaged non-renal clearance; $V_{\mathrm{ss}}$, apparent volume of distribution at steady state; $A e_{0-24 \mathrm{~h}}$, total amount excreted in $24 \mathrm{~h}$ urine.

${ }^{*}$ Mean values for MC-T were significantly different from MC-C $(P<0.05)$.

\section{Discussion}

After the intravenous administration of astaxanthin at doses of 5,10 and $20 \mathrm{mg} / \mathrm{kg}$ in rats, the total amount excreted in $24 \mathrm{~h}$ urine values of astaxanthin were $<0.301 \%$ of the three intravenous doses studied and the contribution of $\mathrm{CL}_{\mathrm{R}}$ to $\mathrm{CL}$ of astaxanthin was almost negligible (Table 1). This suggests that most of the intravenously administrated astaxanthin is eliminated via a non-renal route $\left(\mathrm{CL}_{\mathrm{NR}}\right)$.

After the intravenous administration of astaxanthin, the dose-normalised AUC at $20 \mathrm{mg} / \mathrm{kg}$ was significantly greater than that at $5 \mathrm{mg} / \mathrm{kg}$ (Table 1). This could be due to saturation of hepatic metabolism of astaxanthin. This was supported by the significantly slower $\mathrm{CL}_{\mathrm{NR}}$ of astaxanthin at $20 \mathrm{mg} / \mathrm{kg}$ than at $5 \mathrm{mg} / \mathrm{kg}$. However, after the oral administration of astaxanthin, the AUC were linear between 100 and $200 \mathrm{mg} / \mathrm{kg}$ (Table 1). After the intravenous administration of astaxanthin, the AUC were also linear between 5 and $10 \mathrm{mg} / \mathrm{kg}$ (Table 1). The AUC of intravenous astaxanthin at 5 and $10 \mathrm{mg} / \mathrm{kg}$ (in the linear ranges) were 197 and $488 \mu \mathrm{gmin} / \mathrm{ml}$, respectively (Table 1).
The AUC of oral astaxanthin up to $200 \mathrm{mg} / \mathrm{kg}$ was $150 \mu \mathrm{g} \mathrm{min} / \mathrm{ml}$, smaller than the minimum of $197 \mu \mathrm{g} \mathrm{min} / \mathrm{ml}$ obtained for intravenous condition. Thus, linear AUC after oral administration were expected.

After the oral administration of astaxanthin, its terminal half-lives at 1010-1460 min were considerably longer than the half-lives at $470-569 \mathrm{~min}$ after its intravenous administration (Table 1). This difference could be caused by an absorption pattern of astaxanthin that follows the flip-flop model. When absorption is considerably slower than elimination, that is, if the absorption rate constant is slower than the elimination rate constant, a 'flip-flop' system exists ${ }^{(24)}$. The half-lives of astaxanthin during the absorption phase after the oral administration of astaxanthin were estimated using a residual method; the estimated values were 528 and $550 \mathrm{~min}$ for the astaxanthin oral doses of 100 and $200 \mathrm{mg} / \mathrm{kg}$, respectively, which were close to the half-lives after its intravenous administration (Table 1).

Table 3. Amount of astaxanthin recovered from each gram tissue ( $\mu \mathrm{g} / \mathrm{ml}$ for plasma or $\mu \mathrm{g} / \mathrm{g}$ for other tissues) 8 and $24 \mathrm{~h}$ after its oral administration at a dose of $100 \mathrm{mg} / \mathrm{kg}$ in rats

(Mean values and standard deviations)

\begin{tabular}{|c|c|c|c|c|c|c|}
\hline \multirow[b]{2}{*}{ Tissues } & \multicolumn{3}{|c|}{$8 \mathrm{~h}(n 3)$} & \multicolumn{3}{|c|}{$24 \mathrm{~h}(n 3)$} \\
\hline & Mean & SD & $\mathrm{T} / \mathrm{P}$ ratio & Mean & SD & T/P ratio \\
\hline Plasma & 0.140 & 0.0102 & & 0.0575 & 0.0106 & \\
\hline Brain & 0.260 & 0.265 & 1.96 & 0.123 & 0.0386 & $2 \cdot 14$ \\
\hline Fat & 0.557 & 0.419 & $4 \cdot 13$ & 0.136 & 0.0738 & 2.55 \\
\hline Heart & 0.124 & 0.00568 & 0.890 & 0.109 & 0.493 & 1.99 \\
\hline Kidney & 0.206 & 0.0786 & 1.45 & 0.115 & 0.0468 & $2 \cdot 05$ \\
\hline Liver & 0.140 & 0.00708 & 1.01 & 0.0871 & 0.0082 & 1.533 \\
\hline Lung & 0.151 & 0.0818 & 1.09 & 0.118 & 0.0268 & $2 \cdot 14$ \\
\hline Large intestine & 0.163 & 0.0292 & $1 \cdot 17$ & 0.312 & 0.219 & 5.98 \\
\hline Muscle & 0.216 & 0.198 & 1.62 & 0.143 & 0.0455 & 2.52 \\
\hline Mesentery & 1.59 & 0.991 & $11 \cdot 8$ & 0.0782 & 0.00152 & 1.39 \\
\hline Spleen & 0.156 & 0.102 & $1 \cdot 13$ & 0.0656 & 0.00651 & $1 \cdot 17$ \\
\hline Stomach & $7 \cdot 33$ & $6 \cdot 70$ & $55 \cdot 0$ & $1 \cdot 26$ & 0.426 & $22 \cdot 7$ \\
\hline Small intestine & 0.142 & 0.0215 & 1.02 & 0.139 & 0.0515 & $2 \cdot 52$ \\
\hline
\end{tabular}

T/P ratio, tissue-to-plasma ratios. 
In the present study, the plasma concentrations of 3-hydroxy-4-oxo- $\beta$-ionone and 3-hydroxy-4-oxo-7,8-dihydro- $\beta$-ionone, the metabolites of astaxanthin, were not measured. Their biological activities were not reported in previous studies. Goto et al. ${ }^{(25)}$ suggested that the potent antioxidant activity of astaxanthin was due to its unique structure at the terminal ring moiety. Thus, it could expected that the metabolites of astaxanthin would not seem to be active as antioxidants ${ }^{(25)}$.

The AUC of astaxanthin after its oral administration at a dose of $40 \mathrm{mg}$ in human subjects, $80 \cdot 8 \mu \mathrm{g} \mathrm{min} / \mathrm{ml}^{(8)}$, was close to the AUC of $77.3 \mu \mathrm{g} \mathrm{min} / \mathrm{ml}$ after its oral administration at a dose of $100 \mathrm{mg} / \mathrm{kg}$ in rats (Table 1 ). This suggests that the oral doses of astaxanthin in rats $(100 \mathrm{mg} / \mathrm{kg})$ and human subjects ( $40 \mathrm{mg}$ ) have similar AUC values. The parenteral administration of astaxanthin in clinical research has not been allowed because of its lipophilicity.

Interestingly, the pharmacokinetics of $\beta$-carotene, another carotenoid, is affected by co-administration with other nutrients or drugs. When $\beta$-carotene was given during administration of orlistat, a lipase inhibitor, the absorption of $\beta$-carotene decreased significantly ${ }^{(26)}$. On the other hand, co-administration of $\beta$-carotene resulted in significant reductions in plasma concentrations of $\alpha$-tocopherol or canthaxanthin ${ }^{(27,28)}$. However, limited information has been reported about drug or food interactions of astaxanthin and further studies are needed to clarify the interactions of astaxanthin.

In summary, after the intravenous $(5,10$ and $20 \mathrm{mg} / \mathrm{kg}$ ) and oral (100 and $200 \mathrm{mg} / \mathrm{kg}$ ) administration of astaxanthin, its pharmacokinetic parameters were dose dependent and dose independent, respectively, in rats. The absorption of astaxanthin after oral administration followed the flip-flop model. The hepatic and gastrointestinal first-pass extraction ratios were approximately 0.490 and 0.901 , respectively. Astaxanthin was unstable up to a $4 \mathrm{~h}$ incubation in the rat gastric juices and $24 \mathrm{~h}$ incubation in various buffer solutions having $\mathrm{pH}$ of $1-13$.

\section{Acknowledgements}

The present work was supported by a grant of the Korea Health 21 R\&D project, Ministry of Health and Welfare, Korea (A050376). The contributions of the authors to the manuscript are as follows: H. D. C. designed and conducted the study, analysed the data and wrote the paper; H. E. K. and S. H. Y. conducted the study; M. G. L. and W. G. S. designed the study and reviewed the manuscript. All the authors read and approved the final manuscript. There are no conflicts of interest to declare.

\section{References}

1. Higuera-Ciapara I, Félix-Valenzuela L \& Goyocoolea FM (2006) Astaxanthin: a review of its chemistry and applications. Crit Rev Food Sci Nutr 46, 186-196.
2. Miki W (1991) Biological functions and activities of animal carotenoids. Pure Appl Chem 63, 141-146.

3. Pashkow FJ, Watumull DG \& Campbell CL (2008) Astaxanthin: a novel potential treatment for oxidative stress and inflammation in cardiovascular disease. Am J Cardiol 101, 58D-68D

4. Comhaire FH, El Garem Y, Mahmoud A, et al. (2008) Combined conventional/antioxidant 'astaxanthin' treatment for male infertility: a double blind, randomized trial. Asian J Androl 7, 257-262.

5. Kupcinskas L, Lafolie P, Lignell A, et al. (2008) Efficacy of the natural antioxidant astaxanthin in the treatment of functional dyspepsia in patients with or without Helicobacter pylori infection: a prospective, randomized, double blind, and placebo-controlled study. Phytomedicine 15, 391-399.

6. Parisi V, Tedeschi M, Gallinaro G, et al. (2008) Carotenoids and antioxidants in age-related maculopathy Italian study: multifocal electroretinogram modifications after 1 year. Ophthalmology 115, 324-344.

7. Nagao A (2009) Absorption and function of dietary carotenoids. Forum Nutr 61, 55-63.

8. Odeberg JM, Lignell A, Pettersson A, et al. (2003) Oral bioavailability of the antioxidant astaxanthin in humans is enhanced by incorporation of lipid based formulations. Eur J Pharm Sci 19, 299-304.

9. Okada Y, Ishikura M \& Maoka T (2009) Bioavailability of astaxanthin in Haematococcus algal extract: the effects of timing of diet and smoking habits. Biosci Biotechnol Biochem 73, 1928-1932.

10. Showalter LA, Weinman SA, Østerlie M, et al. (2004) Plasma appearance and tissue accumulation of non-esterified, free astaxanthin in $\mathrm{C} 57 \mathrm{BL} / 6$ mice after oral dosing of a disodium disuccinate diester of astaxanthin (Heptax). Comp Biochem Physiol C Toxicol Pharmacol 137, 227-236.

11. Petri D \& Lundebye AK (2007) Tissue distribution of astaxanthin in rats following exposure to graded levels in the feed. Comp Biochem Physiol C Toxicol Pharmacol 145, 202-209.

12. Kistler A, Liechti H, Pichard L, et al. (2002) Metabolism and CYP-inducer properties of astaxanthin in man and primary human hepatocytes. Arch Toxicol 75, 665-675.

13. Erich W, Hans L, Brightte N, et al. (1999) Characterization of metabolites of astaxanthin in primary cultures of rat hepatocytes. Drug Metab Dispos 27, 456-462.

14. Correia MA (1995) Appendices B. Rat and human liver cytochromes 450: substrate and inhibitor specificities and functional markers. In Cytochrome 450. Structure, Mechanism, and Biochemistry, 2nd ed., pp. 607-630. New York: Plenum Press.

15. Kim SH, Choi YM \& Lee MG (1993) Pharmacokinetics and pharmacodynamics of furosemide in protein-calorie malnutrition. J Pharmacokinet Biopharm 21, 1-7.

16. Murakami T, Nakanishi M, Yoshimori T, et al. (2003) Separate assessment of intestinal and hepatic first-pass effects using a rat model with double cannulation of the portal and jugular veins. Drug Metab Pharmacokinet 18, 242-260.

17. Choi YH, Kim SG \& Lee MG (2006) Dose-independent pharmacokinetics of metformin in rats: hepatic and gastrointestinal first-pass effects. J Pharm Sci 95, 2543-2552.

18. Williams JF, Lowitt S \& Szentivanyi A (1979) Effect of phenobarbital and 3-methylcholanthrene pretreatment on the plasma half-life and urinary excretion profile of theophylline and its metabolites in rats. Biochem Pharmacol 28, 2935-2940.

19. Choi YM, Kim SH \& Lee MG (1991) Effect of phenobarbital and 3-methylcholanthrene pretreatment on the pharmacokinetics and pharmacodynamics of furosemide in rats. J Pharm Sci 80, 638-642. 
20. Lee DY, Kim JY, Kim YC, et al. (2005) Dose-independent pharmacokinetics of torasemide after intravenous and oral administration to rats. Biopharm Drug Dispos 26, 173-182.

21. Yu SY, Bae SK \& Kim EJ (2003) Dose-independent pharmacokinetics of a new reversible proton pump inhibitor, KR-60436, after intravenous and oral administration to rats: gastrointestinal first-pass effect. J Pharm Sci 92, $1592-1603$.

22. Gibaldi M \& Perrier D (1980) Pharmacokinetics, 2nd ed. New York: Marcel Dekker.

23. Chiou WL (1978) Critical evaluation of potential error in pharmacokinetic studies using the linear trapezoidal rule method for the calculation of the area under the plasma level-time curve. J Pharmacokinet Biopharm 6, 539-546.

24. Boxenbaum H (1998) Pharmacokinetics tricks and traps: flip-flop models. J Pharm Pharm Sci 1, 90-91.
25. Goto S, Kogure K, Abe K, et al. (2001) Efficient radical trapping at the surface and inside the phospholipid membrane is responsible for highly potent antiperoxidative activity of the carotenoid astaxanthin. Biochim Biophys Acta 1512, 251-258.

26. Zhi J, Melia AT, Koss-Twardy SG, et al. (1996) The effect of orlistat, an inhibitor of dietary fat absorption, on the pharmacokinetics of beta-carotene in healthy volunteers. $J$ Clin Pharmacol 36, 152-159.

27. Xu MJ, Plezia PM, Alberts DS, et al. (1992) Reduction in plasma or skin alpha-tocopherol concentration with longterm oral administration of beta-carotene in humans and mice. J Natl Cancer Inst 84, 1559-1565.

28. White WS, Stacewicz-Sapuntzakis M, Erdman JW Jr, et al. (1994) Pharmacokinetics of beta-carotene and canthaxanthin after ingestion of individual and combined doses by human subjects. J Am Coll Nutr 13, 665-671. 